\title{
LXV. Notice of some experiments which show a repulsive action between heated surfaces and certain pulverulent bodies
}

\section{R. Addams Esq.}

To cite this article: R. Addams Esq. (1835) LXV. Notice of some experiments which show a repulsive action between heated surfaces and certain pulverulent bodies, Philosophical Magazine Series 3, 6:36, 415-417, DOI: 10.1080/14786443508648635

To link to this article: http://dx.doi.org/10.1080/14786443508648635

曲 Published online: 01 Jun 2009.

Submit your article to this journal $[\pi$

Џll Article views: 3

Q View related articles $₫$ 
rections and extensions of the theory of electro-chemical decomposition, given in the Fifth and Seventh Series of these Researches. The expressions I would now alter are those which relate to the independence of the evolved elements of the poles or electrodes, and the reference of their evolution to powers entirely internal (524.537.661.). The present paper fully shows my present views; and I would refer to paragraphs 891.904.910. 917.918.947.963. 1007.1031. \&c., as stating what they are. I hope this note will be considered as sufficient in the way of correction at present; for I would rather defer revising the whole theory of electro-chemical decomposition until I can obtain clearer views of the way in which the power under consideration can appear at one time as associated with particles giving them their chemical attraction, and at another as fiee electricity (493.957.). - M. F.

Royal Institution, March 31, 1834.

LXV. Notice of some Experiments which show a repulsive Action between heated Surfaces and certain pulverulent Bodies. By R. Addams, Esq., Lecturer on Chemistry and Natural Philosophy*.

THAT caloric possesses a repellent force is assumed from the effects it produces upon matter in general: but there are those who do not allow that we have any unequivocal evidence of calorific repulsion between independent bodies, such, for example, as two separate masses of heated iron; indeed, the question whether caloric does not act repulsively at sensible distances, has recently been made the subject of experimental investigation by the Rev. Professor Powellt, who, in the Philosophical 'Transactions for the last year, has given an account of an elegant and refined mode of testing the repulsion between two heated lenticular masses of glass.

The following description of some experiments which seen to bear upon the question may not, therefore, be unacceptable to those who are interested in this branch of inquiry.

Exp. 1. A small quantity of silica (prepared by precipitation from its alkaline solution) was heated upon a platinum capsule: when the heat-that from a spirit-lamp-had acted for a second or two, the powder moved, by the least motion of the capsule, as if it were floating upon a liquid, having a mobility almost equal to that of mercury. The fric-

* Communicated by the Author.

† Lond. and Edinb. Phil. Mag., vol. vi. p. 58. 
tion between the metal and silica was so trifling that the latter would often remain stationary, whilst the former slid beneath it; and when the capsule was moved, by the hand, circularly in one direction, the powder would revolve the contrary way. The effect ceases almost instantly by a removal from the lamp, and is renewed as often as it is reheated. Whilst subjected to the flame of the lamp, if touched with a cold body, as a metallic wire or glass rod, it would somelimes lose its peculiar freedom to glide about, and then rest upon the platinum vessel sluggish and immoveable otherwise than with the vessel itself.

Exp. 2. Supposing it possible that moisture might interfere, I introduced another portion of silica into a glass flask, mounted with a stop-cock, and heated it to a temperature of from $300^{\circ}$ to $500^{\circ}$, in which state it was kept for a week with the valve closed. After the first action of the heat to expel a part of the air, it still continued to exhibit the same phænomenon as before in the open vessel. The air was additionally rarified by an air-pump, but with no alteration in the behavour of the powder.

Exp. 3. Magnesia, peroxide of copper, sesquioxide of lead, peroxide of cobalt, oxide of nickel, peroxide of manganese, and smalt, were successively heated as in Exp. 1, and with correspondent results.

On the other hand, oxide of chromium, litharge, and alumina afforded little or no evidence of such peculiarity.

Remembering Dr. Faraday's experiment " on the electric powers of oxalate of lime*," I subjected that compound to a similar trial ; and obtained evidence of the same kind of motion as before (1.), yet in a less degree than with silica and the substances named in No. 3. from magnesia to smalt inclusive.

The powders were more or less in an electric state, but this (the electricity,) I regard as an accompaniment, and not as the cause of the free motion of the powders upon the metal; for touching the metal with good conductors of electricity made no alteration save that which could fairly be assigned to the cooling effect upon the platinum or glass capsules, both having been employed. Also by insulating the platinum no difference was noticed.

In Dr. Faraday's experiment before referred to, the oxalate of lime was electrified, positively, by stirring it with a rod or spatula, whereas the diminished friction or contact between the bodies concerned in the experiments now described took place without stirring or previous agitation.

* Journal of the Royal Institution, vol, xix. p. 338 . 
The quantities of the powders which I have hitherto employed have been too small, (not exceeding 30 or 40 grains, to decide upon their electrical states in a satisfactory manner.

Before I conclude the present communication, I will advert to a simple experiment, which is familiar to many, I have no doubt, and which bears upon the subject under consideration.

Thus: take up a small portion of tallow at the end of a wire; hold the latter inclined to the horizon and with the hand uppermost; thrust the tallow into the flame of a candle, and it will be seen to react from the heat and run up the wire, in a melted state, to the distance of an inch or more. Professor Stevelly alluded to this experiment in reference to the repulsive agency of heat, at the meeting of the British Association in Edinburgh.

Kensington, January 6, 1835.

LXVI. On Water as a Constituent of Salts. In the Case of Sulphates. By Thomas Graham, F.R.S.E., Andersonian Professor of Chemistry and Vice-President of the Philosophical Society of Glasgoro.

[Continued from p. 334, and concluded.]

Sulphate of Zinc with Sulphate of Soda: $\dot{\mathrm{Z}} \dddot{\mathrm{S}}(\dot{\mathrm{NaS}})+\dot{\mathrm{H}}^{4}$. Sulphate of Zinc and Soda.

THIS salt, I believe, has not hitherto been described. I failed in attempting to form it, by dissolving together sulphate of zinc and sulphate of soda in atomic proportions : the salts uniformly crystallized apart, either in cold or in warm weather. Each of the salts was also added in excess to the other, but with no better effect. It appears, then, that sulphate of soda does not displace the saline water of sulphate of zinc, so easily as sulphate of potash does. But the desired salt was obtained by a process of double decomposition, suggested from consideration of the relations of the sulphates. Solutions of bisulphate of soda, and of sulphate of zinc, were mixed together in atomic proportions, from which the sulphate of zinc and soda separated in a gradual manner in the course of a day or two, leaving sulphuric acid in solution.

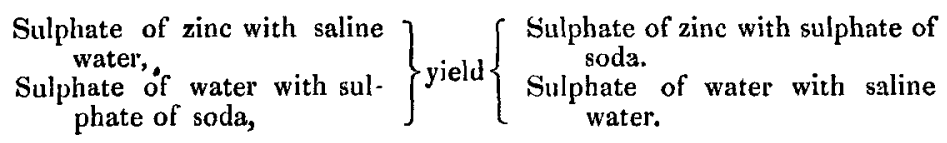

This salt is deposited in distinct tabular crystals, of a pecuThird Series. Vol. 6. No.36. June $1835 . \quad 3 \mathrm{H}$ 